\title{
Chapter 19 \\ Development and Performance of Low-Cost Beta-Type Ti-Based Alloys for Biomedical Applications Using Mn Additions
}

\author{
Pedro F. Santos, Mitsuo Niinomi, Huihong Liu, Masaaki Nakai, Ken Cho, \\ Takayuki Narushima, Kyosuke Ueda, Naofumi Ohtsu, Mitsuhiro Hirano, \\ and Yoshinori Itoh
}

\begin{abstract}
The microstructures, mechanical properties, and biocompatibility of various low-cost $\beta$-type Ti-Mn alloys fabricated by both cold crucible levitation melting (CCLM) and metal injection molding (MIM) were investigated after solution treatment. Mn was chosen as a potential low-cost alloying element for Ti. Among the alloys fabricated by both methods, Ti-9Mn shows the best combination of tensile strength and elongation, and their performances are mostly comparable to or superior to those of Ti-6Al-4V (Ti-64) ELI. However, alloys fabricated by MIM show a higher $\mathrm{O}$ and $\mathrm{C}$ content, along with precipitated Ti carbides and pores, which all cause the ductility of the alloys fabricated by MIM to be lower than that of the alloys fabricated by CCLM. Furthermore, the cell viability and metallic ion release ratios of the alloys fabricated by CCLM are comparable to those of commercially pure Ti, making this alloy promising for biomedical applications. The Young's modulus of the alloys is also lower than that of Ti-64 ELI (which is of approximately 110 $\mathrm{GPa}$ ), which can possibly reduce the stress shielding effect in implanted patients.
\end{abstract}

\author{
P.F. Santos $(\bowtie) \bullet$ T. Narushima $\bullet$ K. Ueda \\ Department of Materials Processing, Tohoku University, 6-6-02 Aza Aoba, Aramaki, \\ Aoba-ku, Sendai, Miyagi 980-8579, Japan \\ e-mail: pedro@imr.tohoku.ac.jp \\ M. Niinomi \\ Institute for Materials Research, Tohoku University, \\ 2-1-1 Katahira, Aoba-ku, Sendai, Miyagi 980-8577, Japan \\ Graduate School of Science and Technology, Meijyo University, \\ 1-501, Shiogamaguchi, Tempaku-ku, Nagoya, Aichi 468-8502, Japan \\ Graduate School of Engineering, Osaka University, \\ 2-1 Yamadagaoka, Suita, Osaka 565-0871, Japan \\ Institute of Materials and Systems for Sustainability, Nagoya University, \\ Furo-cho, Chikusa-ku, Nagoya, Aichi 464-8603, Japan \\ H. Liu \\ Joining and Welding Research Institute, Osaka University, \\ 11-1 Mihogaoka, Suita, Osaka 567-0047, Japan


Keywords Ti-Mn alloys $\bullet \beta$ phase $\bullet$ Mechanical properties $\bullet$ Metallic biomaterials - Low-cost Ti alloy

\subsection{Introduction}

Among the most widely used metallic biomaterials, titanium (Ti) and its alloys are the most suitable because of their high specific strength, good corrosion resistance, and biocompatibility [1-3]. However, the most widely used Ti-based alloys in biomedical applications were not designed for this kind of application and can show issues. Commercially pure $\mathrm{Ti}$ (CP-Ti) has insufficient mechanical properties for some biomedical applications, whereas Ti-6Al-4V (Ti-64) ELI has the necessary mechanical properties, but contains $\mathrm{Al}$ and $\mathrm{V}$, which can be released as ions from the alloy and are associated to health issues in the human body [2, 4-8]. Therefore, recent efforts have been made in recent years to produce new and more biocompatible $\beta$-type Ti alloys, designed specifically for biomedical applications [3]. $\beta$-type Ti alloys can achieve the highest specific strength when compared with $\alpha$ - or $(\alpha+\beta)$ type Ti alloys [9]. Furthermore, $\beta$ stabilizing alloying elements can contribute to reduce the Young's modulus of the alloys $[10,11]$. The lower Young's modulus is useful because metallic biomaterials usually have a Young's modulus much higher than that of the human bone, which can end up causing the stress shielding effect [12]. However, many of the newly developed alloys contain scarce and high-cost elements such as $\mathrm{Nb}$ and $\mathrm{Ta}$, which may be difficult to obtain in the future because of the limited amounts of their natural deposits [13, 14].

Considering the abovementioned factors (i.e., biocompatibility, balance of mechanical properties, availability, and cost), Mn was selected as the primary alloying element for Ti-Mn system alloys due to its $\beta$ stabilizing effect, lower cytotoxicity, higher availability, and lower cost when compared to other popular alloying elements $[15,16]$. Some of the binary Ti-Mn alloys fabricated using a cold crucible

\footnotetext{
M. Nakai

Department of Mechanical Engineering, Faculty of Science and Engineering,

Kindai University, 3-4-1 Kowakae, Higashiosaka, Osaka 577-8502, Japan

K. Cho

Graduate School of Engineering, Osaka University,

2-1 Yamadaoka, Suita, Osaka 565-0871, Japan

N. Ohtsu $\bullet$ M. Hirano

Instrument Analysis Center, Kitami Institute of Technology,

165 Koen-Cho, Kitami, Hokkaido 090-8507, Japan

Y. Itoh

Hamamatsu Technical Support Center, Industrial Research Institute of Shizuoka Prefecture, 1-3-3 Shinmiyakoda, Kita-ku, Hamamatsu, Shizuoka 431-2103, Japan
} 
levitation melting (CCLM) showed a performance comparable or superior to that of the Ti-64 ELI for biomedical applications [15]. Furthermore, Ti-Mn alloys containing up to 13 mass \% Mn showed cytotoxicity levels comparable to that of CP-Ti, but the alloy containing 18 mass $\%$ Mn showed cytotoxicity [15]. Thereafter, further cost reduction was considered by fabricating Ti-Mn alloys using a metal injection molding (MIM), a powder metallurgy near-net shape fabrication method [16]. The alloys fabricated by MIM showed some mechanical properties comparable to those of the alloys fabricated by CCLM, but because of both high porosity and high amount of interstitial impurities - inherent to the fabrication method - there was a drastic decrease in ductility compared to the alloys fabricated using CCLM [16]. Therefore, it is necessary to improve the ductility of the alloys.

\subsection{Experimental Procedures}

\subsubsection{Ingots Preparation}

For the first part of this study, ingots of Ti-(6, 9, 13, and 18 mass\%)Mn were fabricated by CCLM. The ingots were initially subjected to a homogenization treatment for $21.6 \mathrm{ks}$ at $1,273 \mathrm{~K}$ followed by ice water quenching and then to hot forging and hot rolling, both at $1,173 \mathrm{~K}$. Finally, in order to retain the $\beta$ phase in the alloys, the plates were subjected to solution treatment for $3.6 \mathrm{ks}$ at $1,173 \mathrm{~K}$ in vacuum, followed by ice water quenching. Hereafter, the alloys fabricated by CCLM will be identified by the subscript "LM," as in Ti-Mn $\mathrm{LM}_{\mathrm{LM}}$.

For the second part of this study, ingots of Ti-(8, 9, 12, 13, 15, and 17 mass\%)Mn were fabricated by MIM. Sintering was conducted in vacuum at $1,373 \mathrm{~K}$ for $28.8 \mathrm{ks}$. Finally, in order to retain the $\beta$ phase in the alloys, the plates were subjected to solution treatment for $3.6 \mathrm{ks}$ at $1,173 \mathrm{~K}$ in vacuum, followed by ice water quenching. Further details on the specimen preparation methods are described elsewhere [16]. Hereafter, the alloys fabricated by MIM will be identified by the subscript "MIM," as in $\mathrm{Ti}-\mathrm{Mn}_{\mathrm{MIM}}$.

\subsubsection{Microstructure Characterization}

For all parts of this study, the material characterization was performed by chemical composition analysis, optical microscopy (OM), X-ray diffractometry (XRD), and transmission electron microscopy (TEM). Furthermore, electron probe microanalysis (EPMA) was carried out on the alloys fabricated by MIM. The experimental conditions and other details are described elsewhere $[15,16]$. 


\subsubsection{Mechanical Properties Evaluation}

For all parts of this study, the mechanical property investigation was conducted by means of Vickers hardness tests, Young's modulus measurements, and tensile tests. Furthermore, compressive tests were carried out on the alloys fabricated by MIM. The experimental conditions and other details are described elsewhere $[15,16]$.

\subsubsection{Biocompatibility Evaluation}

The biocompatibility of the alloys fabricated by CCLM was evaluated by means of immersion tests in simulated body fluids (SBF), followed by X-ray photoelectron spectroscopy (XPS) of the surface of SBF-immersed samples, and also cytotoxicity tests using MC3T3-E1 cells. The experimental conditions and other details are described elsewhere [15].

\subsection{Results and Discussion}

\subsubsection{Ti-Mn Binary Alloys Fabricated by CCLM}

Table 19.1 shows the chemical compositions of Ti-(6-18) $\mathrm{Mn}_{\mathrm{LM}}$. The lower amount of $\mathrm{Mn}$ content in comparison to the nominal value is caused by the evaporation of Mn during melting processes [17]. Mn loss of up to $25 \%$ was expected [17]. However, the observed difference $(2-10 \%)$ is considerably smaller in the $\mathrm{Ti}-\mathrm{Mn}_{\mathrm{LM}}$, thanks to the shorter melting time required by this method.

Figures 19.1 and 19.2 show the optical micrographs and XRD profiles of the Ti-(6-18) $\mathrm{Mn}_{\mathrm{LM}}$, respectively. As shown in Fig. 19.2, only diffraction peaks attributed to $\beta$ planes are detected in the XRD profiles of Ti-(9-18) $\mathrm{Mn}_{\mathrm{LM}}$. However, diffraction peaks that can be attributed to $\omega$ and $\alpha$ or $\alpha^{\prime}$ phases are also detected in the XRD profile of Ti-6Mn $\mathrm{MM}_{\mathrm{LM}}$. A concentration of approximately 6.3 mass $\% \mathrm{Mn}$ is required to fully retain the $\beta$ phase upon quenching [4]. However, the Mn content of $\mathrm{Ti}-6 \mathrm{Mn}_{\mathrm{LM}}$ used for this study is 5.60 mass $\%$. Furthermore, the presence of the athermal $\omega$ phase has been confirmed by the TEM observations. Figure $19.3 \mathrm{a}-\mathrm{d}$ shows

Table 19.1 Chemical compositions of Ti-Mn alloys fabricated by CCLM (mass\%)

\begin{tabular}{|c|c|c|c|c|c|c|}
\hline \multirow[b]{2}{*}{ Alloy } & \multicolumn{5}{|c|}{ Element } & \multirow[b]{2}{*}{ Nominal Mn } \\
\hline & $\mathrm{Ti}$ & Mn & $\mathrm{O}$ & $\mathrm{C}$ & $\mathrm{N}$ & \\
\hline Ti-6Mn $\mathrm{MM}_{\mathrm{LM}}$ & bal. & 5.60 & 0.0736 & 0.0036 & 0.0045 & 6.0 \\
\hline Ti-9Mn & bal. & 9.47 & 0.0727 & 0.0031 & 0.0036 & 10.0 \\
\hline Ti-13Mn $\mathrm{MM}_{\mathrm{LM}}$ & bal. & 12.65 & 0.0747 & 0.0024 & 0.0043 & 14.0 \\
\hline Ti-18Mn $\mathrm{MM}_{\mathrm{LM}}$ & bal. & 17.65 & 0.0591 & 0.0073 & 0.0021 & 18.0 \\
\hline
\end{tabular}




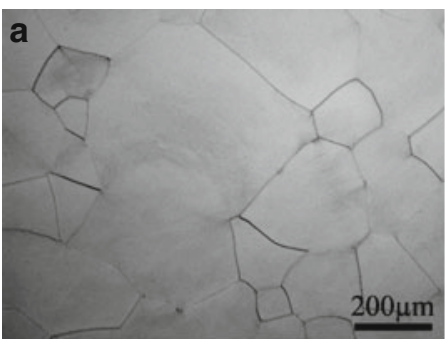

$\mathrm{Ti}^{-}-6 \mathrm{Mn}_{\mathrm{LM}}$

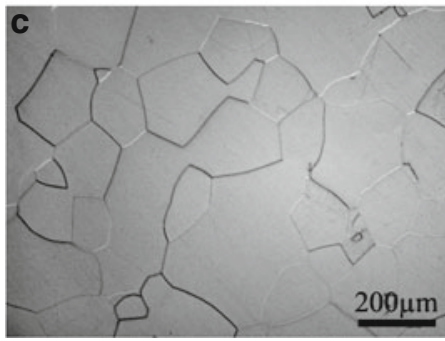

$\mathrm{Ti}-13 \mathrm{Mn}_{\mathrm{LM}}$

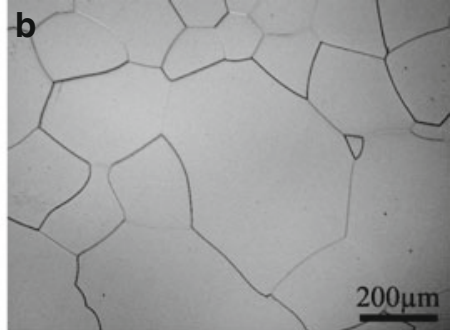

Ti-9Mn $\mathrm{MM}_{\mathrm{L}}$

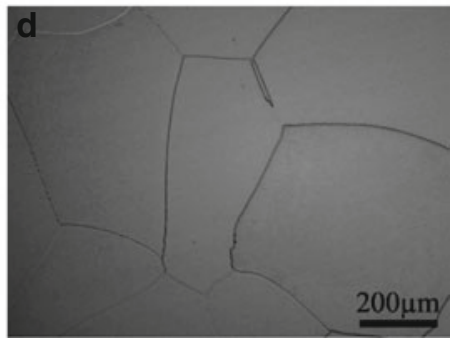

$\mathrm{Ti}-18 \mathrm{Mn}_{\mathrm{LM}}$

Fig. 19.1 Typical optical micrographs of (a) $\mathrm{Ti}-6 \mathrm{Mn}_{\mathrm{LM}}$, (b) $\mathrm{Ti}-9 \mathrm{Mn}_{\mathrm{LM}},(\mathbf{c}) \mathrm{Ti}-13 \mathrm{Mn}_{\mathrm{LM}}$, and (d) $\mathrm{Ti}-18 \mathrm{Mn}_{\mathrm{LM}}$
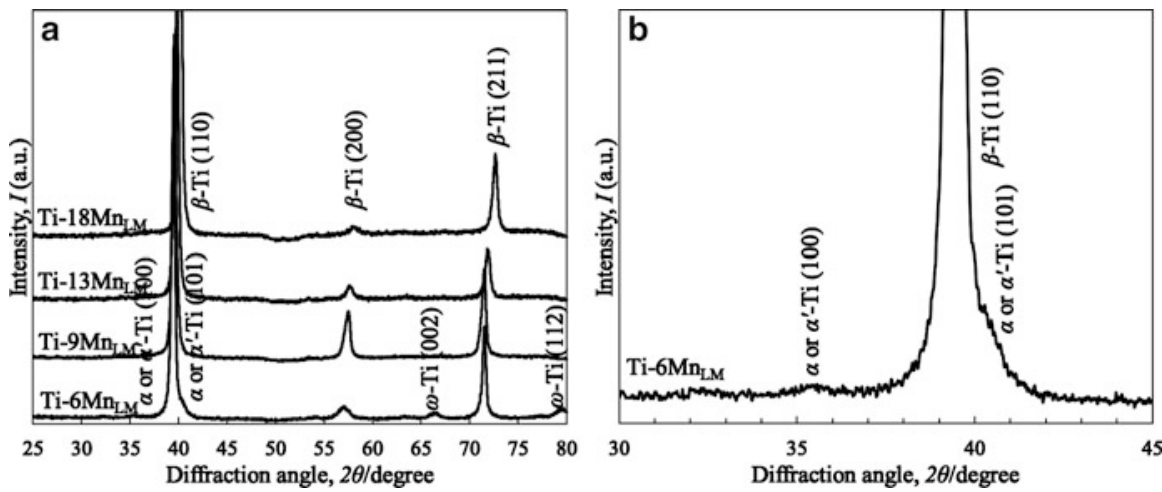

Fig. 19.2 (a) XRD profiles of Ti-Mn $\mathrm{LM}_{\mathrm{LM}}$ alloys and (b) magnified section of XRD profile of $\mathrm{Ti}-6 \mathrm{Mn}_{\mathrm{LM}}$

the selected area electron diffraction (SAED) patterns, where the spots or streaks attributed to the athermal $\omega$ phase decrease in intensity with increasing Mn content. The bright particles in the corresponding dark field (DF) images (Fig. 19.3e-h) represent the athermal $\omega$ phase particles. Ti- $6 \mathrm{Mn}_{\mathrm{LM}}$ contains the largest amount of particles, as it decreases with increasing Mn content. The decrease in the volume fraction of the athermal $\omega$ phase, observed through the DF images of the Ti-(6-18) 


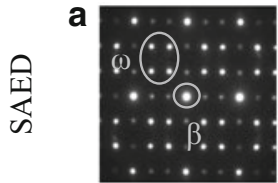

Ti-6Mn $\mathrm{MM}_{\mathrm{L}}$

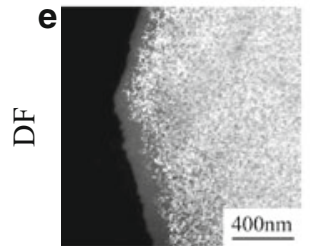

Ti-6Mn $\mathrm{MM}_{\mathrm{LM}}$

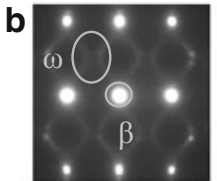

Ti-9Mn ${ }_{\mathrm{LM}}$

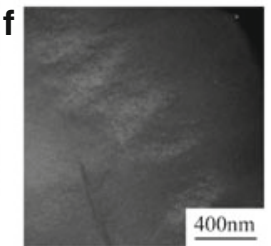

Ti-9Mn ${ }_{\text {LM }}$

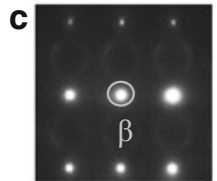

Ti-13Mn ${ }_{\mathrm{LM}}$

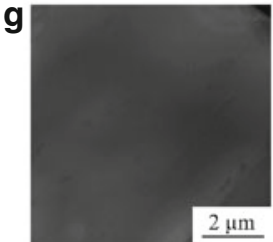

Ti-13Mn ${ }_{\mathrm{LM}}$

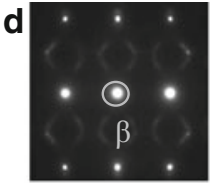

$\mathrm{Ti}-18 \mathrm{Mn}_{\mathrm{LM}}$

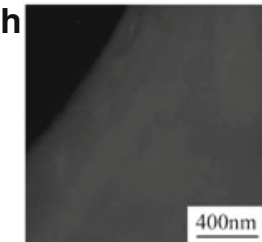

Ti-18Mn ${ }_{\text {LM }}$

Fig. 19.3 Typical SAED patterns viewed from $[110]_{\beta}$, and corresponding DF images of diffraction spots or streaks of $\omega$ phase of (a) and (e) Ti-6 $\mathrm{Mn}_{\mathrm{LM}}$, (b) and (f) $\mathrm{Ti}-9 \mathrm{Mn}_{\mathrm{LM}},(\mathbf{c})$ and (g) $\mathrm{Ti}-13 \mathrm{Mn}_{\mathrm{LM}}$, and (d) and (h) $\mathrm{Ti}^{-18 \mathrm{Mn}_{\mathrm{LM}}}$

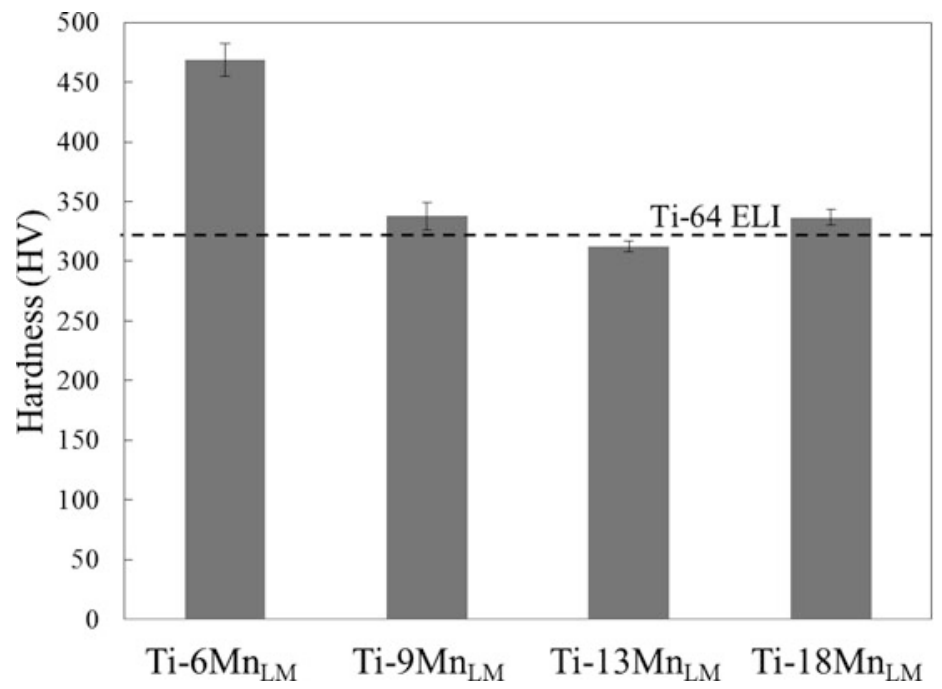

Fig. 19.4 Vickers hardness of Ti-Mn $\mathrm{LM}_{\mathrm{LM}}$ alloys compared to that of Ti-64 ELI alloy (dashed line)

$\mathrm{Mn}_{\mathrm{LM}}$, is attributed to increasing $\beta$ phase stability obtained by increasing the $\mathrm{Mn}$ content. Because of the higher $\beta$ phase stability of the Ti- $13 \mathrm{Mn}_{\mathrm{LM}}$ and Ti- $18 \mathrm{Mn}_{\mathrm{LM}}$, the $\omega$ phase cannot be observed in the DF images of these alloys (Fig. 19.3g, h).

Figures 19.4 and 19.5 show the Vickers hardness and Young's modulus of the $\mathrm{Ti}-(6-18) \mathrm{Mn}_{\mathrm{LM}}$ alloys, respectively. The hardness of Ti-9Mn $\mathrm{LM}_{\mathrm{LM}}$ and $\mathrm{Ti}-13 \mathrm{Mn}_{\mathrm{LM}}$ is comparable to that of Ti-64 ELI reported in the literature (approximately $325 \mathrm{HV}$ ) [5], indicated by the dashed line in Fig. 19.4. Ti-(9-18) $\mathrm{Mn}_{\mathrm{LM}}$ shows a lower value 


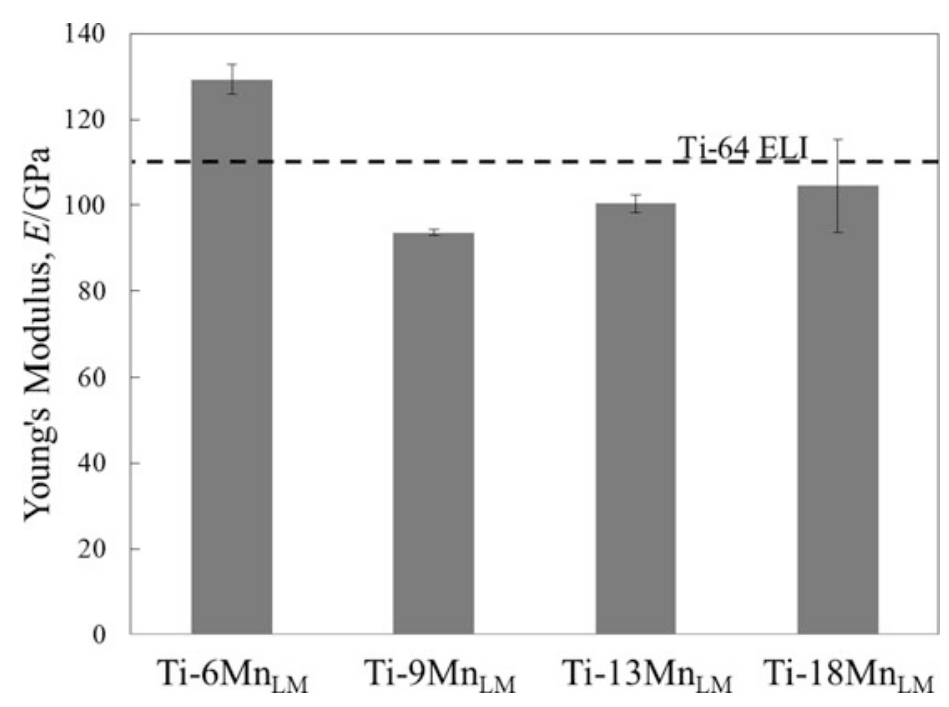

Fig. 19.5 Young's moduli of Ti-Mn $\mathrm{LM}_{\mathrm{LM}}$ alloys compared to that of Ti-64 ELI (dashed line)

of Young's modulus in comparison to that reported for Ti-64 ELI (110 GPa), indicated by the dashed line in Fig. 19.5 [5]. The main factors that affect both the Vickers hardness and Young's modulus measurements of Ti-(6-18) $\mathrm{Mn}_{\mathrm{LM}}$ are the solid solution hardening effects of $\mathrm{Mn}$ and the presence and amount of the athermal $\omega$ phase in the alloys. The increase in Mn leads to an increase in both the Vickers hardness and Young's modulus of the alloys by solid solution hardening and its effect on the lattice, respectively $[15,16,18]$. On the other hand, the decrease in the volume fraction of the athermal $\omega$ phase with increasing Mn leads to a decrease in both Vickers hardness and Young's modulus [4, 19].

Figure 19.6 shows the tensile properties of Ti-(9-18) $\mathrm{Mn}_{\mathrm{LM}}$ along with that of Ti-64 ELI obtained from literature [5]. The tensile properties of Ti-6Mn were not obtained because the specimens suffered premature fracture due to the high amount of athermal $\omega$ phase. Ti- $9 \mathrm{Mn}_{\mathrm{LM}}$ and $\mathrm{Ti}-13 \mathrm{Mn}_{\mathrm{LM}}$ show ultimate tensile strength (UTS, $\left.\sigma_{B}\right), 0.2 \%$ proof stress $\left(\sigma_{0.2}\right)$, and elongation comparable to those reported for Ti-64 ELI $\left(\sigma_{B}: 965 \mathrm{MPa}, \sigma_{0.2}: 869 \mathrm{MPa}\right.$, elongation: $\left.15 \%\right)$ [5]. However, the results shown by $\mathrm{Ti}-9 \mathrm{Mn}_{\mathrm{LM}}\left(\sigma_{B}: 1,048 \mathrm{MPa}, \sigma_{0.2}: 1,023 \mathrm{MPa}\right.$, and elongation: $\left.19 \%\right)$ make the use of this alloy in biomedical applications more promising than either Ti- $13 \mathrm{Mn}_{\mathrm{LM}}$ or Ti-64 ELI.

Figure 19.7 shows the ratio of the amount of released Mn ions to the sum of released Ti and Mn ions to a $1 \%$ lactic acid solution, as a function of Mn content in the Ti-Mn alloys released from the alloys. The ratio of released Mn ions increases in an almost linear relationship with the Mn content observed in the alloys. Concerning the toxic effect of Mn ions released in the human body, adult patients that displayed symptoms related to $\mathrm{Mn}$ intoxication were parenterally administered 


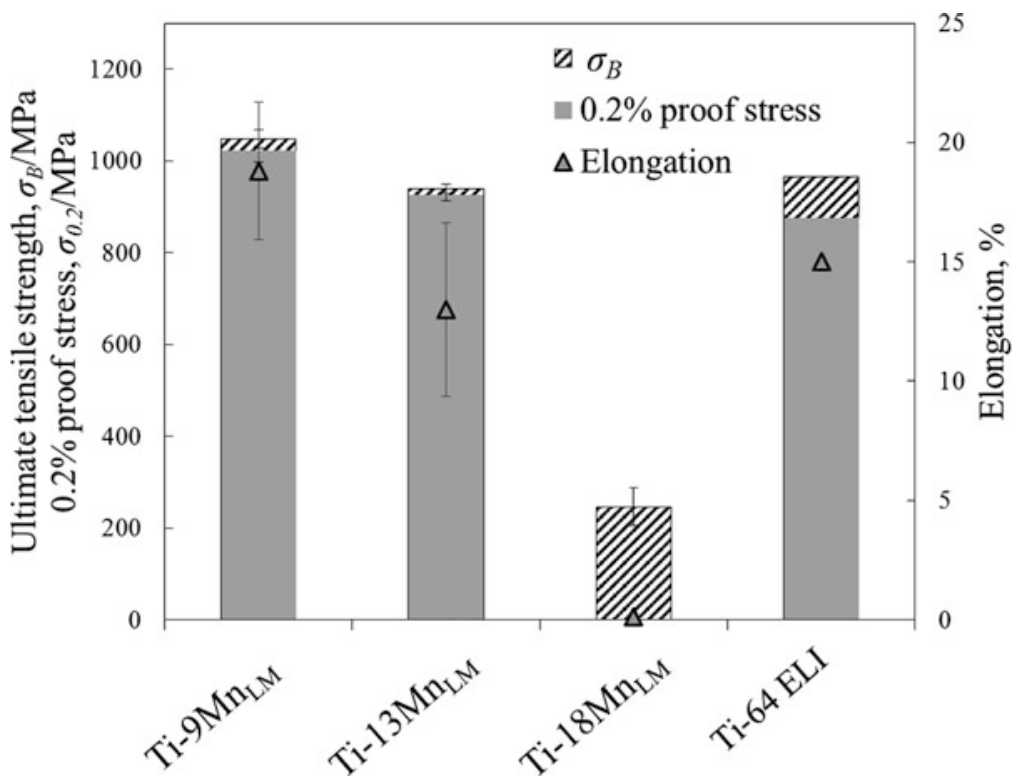

Fig. 19.6 Tensile properties of Ti-Mn $\mathrm{LM}_{\mathrm{LM}}$ alloys along with that of Ti-64 ELI (rightmost column)

Fig. 19.7 Ratio of amount of released $\mathrm{Mn}$ ions to the sum of released $\mathrm{Ti}$ and $\mathrm{Mn}$ ions as a function of $\mathrm{Mn}$ content in the $\mathrm{Ti}-\mathrm{Mn}_{\mathrm{LM}}$ alloys

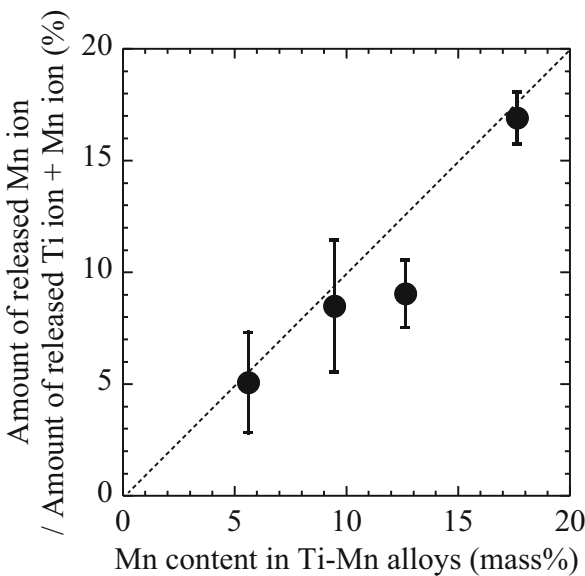

a daily dosage of at least $0.1 \mathrm{mg}$ of $\mathrm{Mn}$ and usually more $[20,21]$. The Ti-Mn $\mathrm{LM}_{\mathrm{LM}}$ alloys immersed in a $1 \%$ lactic acid solution, which is a solution recommended for accelerated immersion tests [22], showed a maximum amount of released Mn ions of approximately $0.9 \mu \mathrm{g} / \mathrm{cm}^{2}(\mathrm{Ti}-18 \mathrm{Mn})$ over a period of 7 days. Because the amount released is orders of magnitude lower than the amount administered during parenteral nutrition, it is believed that the amount of released Mn ions will not reach the levels known to cause symptoms related to Mn intoxication by itself, even in an 


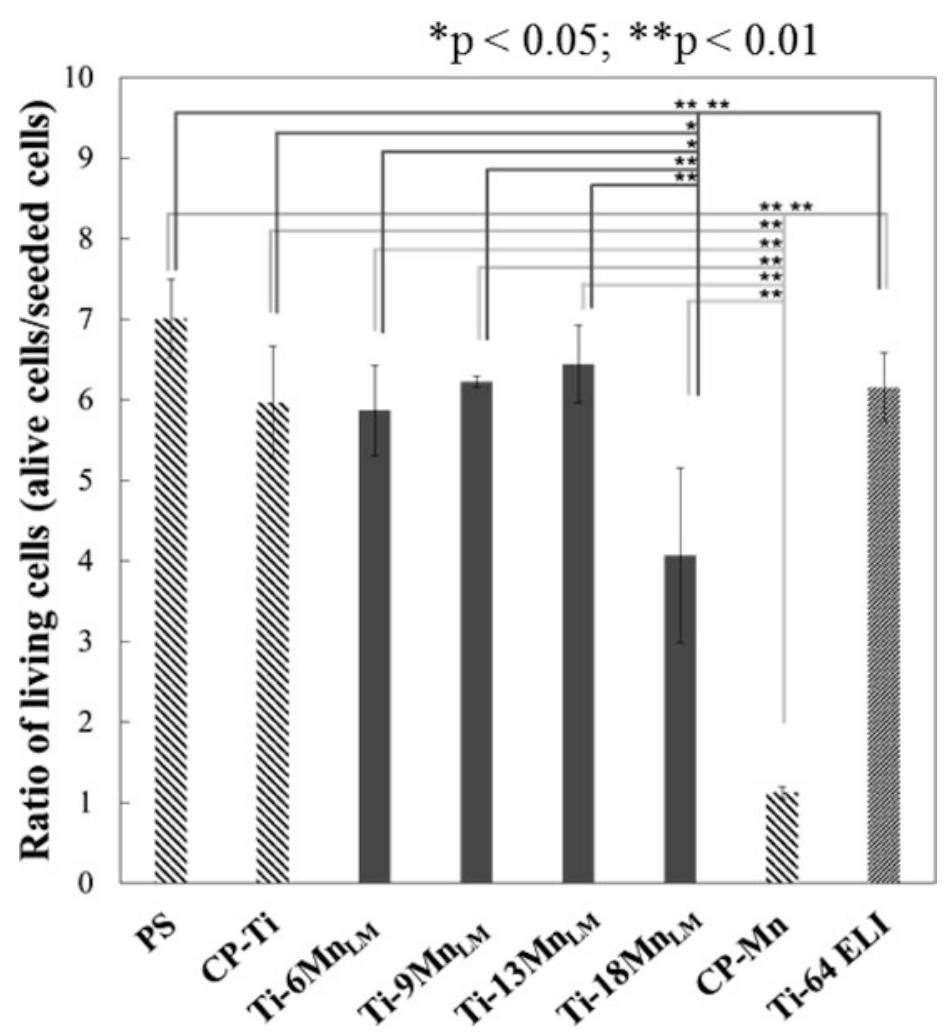

Fig. 19.8 MC3T3-E1 cell viability ratios for the CP-Ti, Ti-Mn $\mathrm{L}_{\mathrm{LM}}$ alloys, and CP-Mn after $72 \mathrm{~h}$ of incubation

implant with considerable surface area. Furthermore, XPS analysis [15] revealed that the immersion tests using $1 \%$ lactic acid caused the passive oxide layer of the alloys to become thinner, but the oxide layer regenerated.

Figure 19.8 shows the results obtained for the cytotoxicity test. After counting the living cells following a $72 \mathrm{~h}$ incubation period, significant differences are observed between Ti-18Mn $\mathrm{MM}_{\mathrm{LM}}, \mathrm{CP}-\mathrm{Mn}$, and the other materials. The cytotoxicity of $\mathrm{Ti}-(6-13) \mathrm{Mn}_{\mathrm{LM}}$ is comparable to that of CP-Ti. The cell proliferations of Ti- $18 \mathrm{Mn}_{\mathrm{LM}}$ and CP-Mn are lower than those of the other alloys. The incubation time of the $72 \mathrm{~h}$ test leads to a higher amount of released $\mathrm{Mn}$ ions from the alloy. It is supposed that the amount of released $\mathrm{Mn}$ ions from $\mathrm{Ti}-18 \mathrm{Mn}_{\mathrm{LM}}$ can inhibit cell proliferation [15].

\subsubsection{Ti-Mn Binary Alloys Fabricated by MIM}

Table 19.2 shows the chemical compositions of $\mathrm{Ti}-(8-17) \mathrm{Mn}_{\text {MIM }}$ fabricated by MIM. The $\mathrm{O}$ content of Ti-(8-17) $\mathrm{Mn}_{\text {MIM }}$ increases with increasing Mn content, from approximately $0.23-0.32$ mass $\%$. Most of the $\mathrm{O}$ present in the alloys originates 


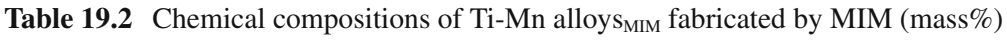

\begin{tabular}{|c|c|c|c|c|c|c|}
\hline \multirow[b]{2}{*}{ Alloy } & \multicolumn{5}{|c|}{ Element } & \multirow[b]{2}{*}{ Nominal Mn } \\
\hline & $\mathrm{Ti}$ & $\mathrm{Mn}$ & $\mathrm{O}$ & $\mathrm{C}$ & $\mathrm{N}$ & \\
\hline $\mathrm{Ti}-8 \mathrm{Mn}_{\mathrm{MIM}}$ & bal. & 7.56 & 0.233 & 0.0606 & 0.0064 & 8.0 \\
\hline Ti-9Mn ${ }_{\text {MIM }}$ & bal. & 9.29 & 0.244 & 0.0654 & 0.0081 & 10.0 \\
\hline $\mathrm{Ti}-12 \mathrm{Mn}_{\mathrm{MIM}}$ & bal. & 11.5 & 0.252 & 0.0604 & 0.0096 & 12.0 \\
\hline $\mathrm{Ti}-13 \mathrm{Mn}_{\mathrm{MIM}}$ & bal. & 13.3 & 0.270 & 0.0512 & 0.0081 & 14.0 \\
\hline $\mathrm{Ti}-15 \mathrm{Mn}_{\mathrm{MIM}}$ & bal. & 15.4 & 0.275 & 0.0655 & 0.0123 & 16.0 \\
\hline Ti-17Mn $\mathrm{MIM}_{\text {MI }}$ & bal. & 17.1 & 0.316 & 0.0512 & 0.0075 & 18.0 \\
\hline
\end{tabular}

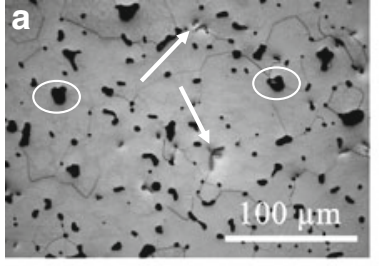

Ti- $8 \mathrm{Mn}_{\mathrm{MIM}}$

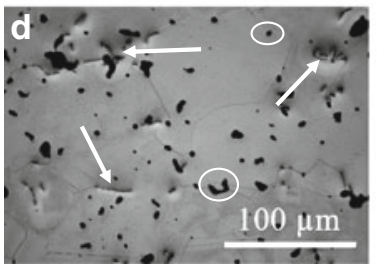

$\mathrm{Ti}-13 \mathrm{Mn}_{\mathrm{MIM}}$

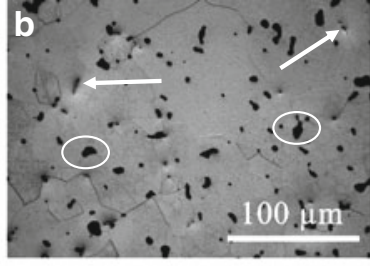

Ti-9 $\mathrm{Mn}_{\mathrm{MIM}}$

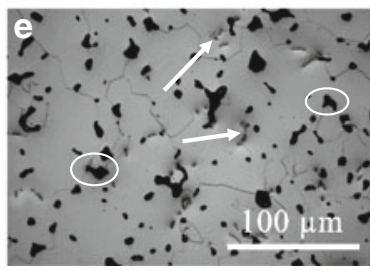

$\mathrm{Ti}-15 \mathrm{Mn}_{\mathrm{MIM}}$

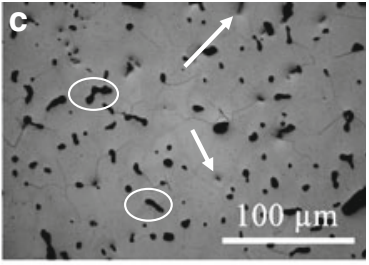

$\mathrm{Ti}-12 \mathrm{Mn}_{\mathrm{MIM}}$

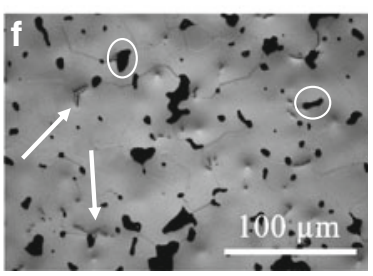

$\mathrm{Ti}-17 \mathrm{Mn}_{\mathrm{MIM}}$

Fig. 19.9 Typical optical micrographs of (a) Ti-8 $\mathrm{Mn}_{\mathrm{MIM}}$, (b) Ti-9Mn

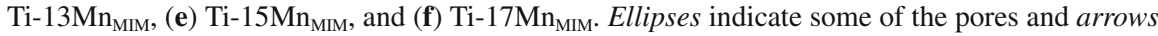
indicate some of the precipitates

from the $\mathrm{Ti}$ and $\mathrm{Mn}$ powders, which contain 0.16 and 0.77 mass $\% \mathrm{O}$, respectively. The $\mathrm{C}$ content of the alloys is of approximately 0.06 mass\%. This is likely due to $\mathrm{C}$ pickup during the debinding process [23]. Furthermore, Mn evaporation is also observed to occur during fabrication by MIM, as the Mn content of the alloys is lower than the nominal content [16].

Figures 19.9 and 19.10 show the optical micrographs and XRD profiles of the Ti-(8-17) $\mathrm{Mn}_{\text {MIM }}$, respectively. Small closed pores, large interconnected pores, and elongated precipitates can be observed in each alloy. Both the pores (ellipses) and precipitates (arrows) are mostly located at the grain boundaries. Only the diffraction peaks of the attributed to $\beta$ planes are observable in the XRD profiles of Ti-(8-17) $\mathrm{Mn}_{\mathrm{MIM}}$. Again, the presence of the athermal $\omega$ phase has been confirmed by the TEM observations. Figure 19.11 shows the SAED patterns and DF images of the diffraction spots or streaks of the $\omega$ phase of Ti-(8-17) $\mathrm{Mn}_{\mathrm{MIM}}$. Clear diffraction spots produced by the athermal $\omega$ phase can be observed in the SAED patterns of 


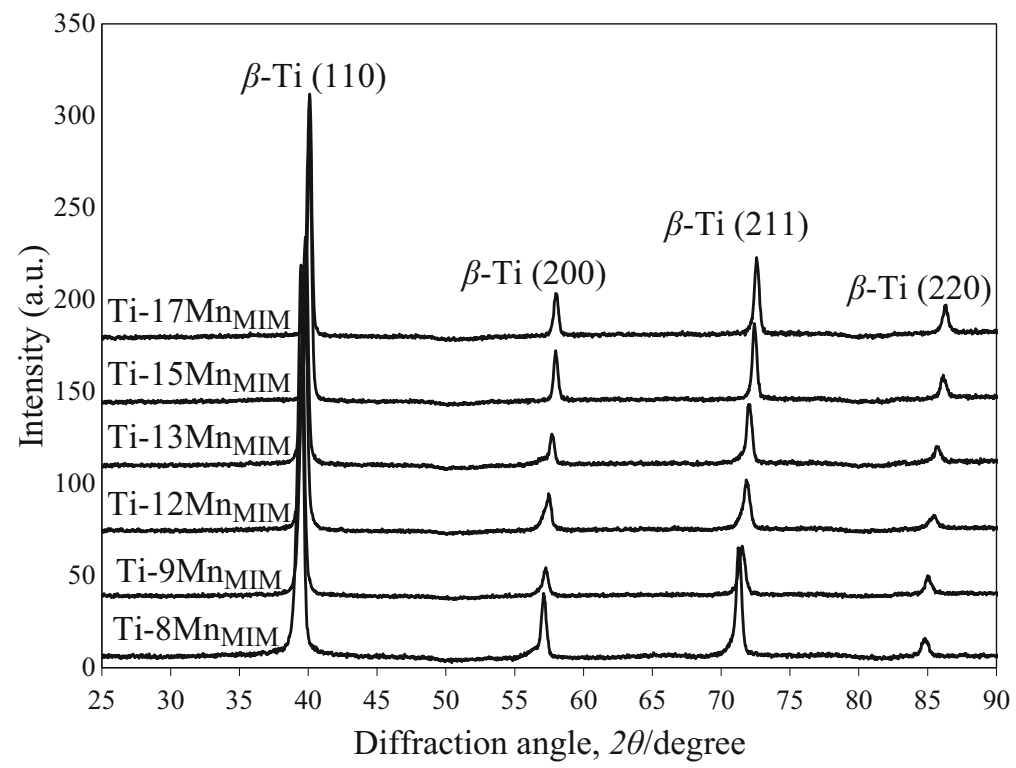

Fig. 19.10 XRD profiles of Ti-Mn $\mathrm{MIM}_{\mathrm{MIM}}$ alloys

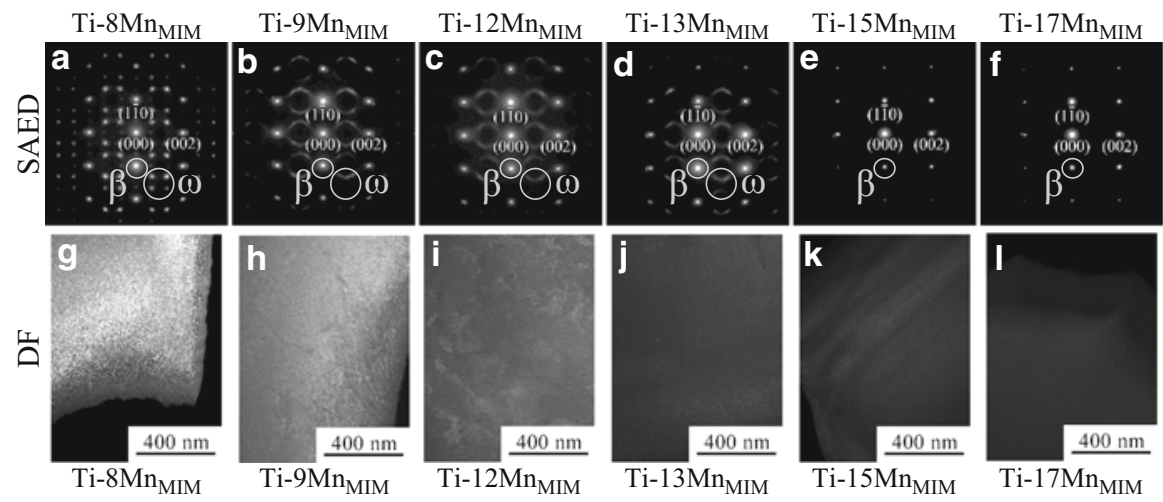

Fig. 19.11 Typical SAED patterns viewed from $[110]_{\beta}$, and corresponding DF images of the dif-

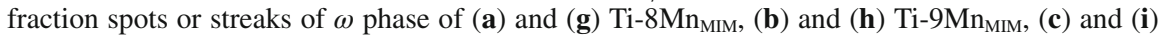

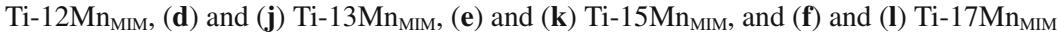

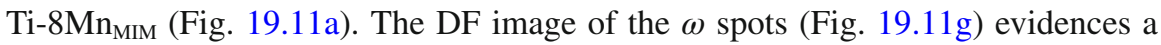
high-volume fraction of the athermal $\omega$ phase of Ti- $8 \mathrm{Mn}_{\text {МIM }}$. The intensity of the spots attributed to the athermal $\omega$ phase and the apparent volume fraction of the athermal $\omega$ particles gradually decrease with increasing Mn content. It is observed that $\mathrm{Ti}-18 \mathrm{Mn}_{\mathrm{LM}}$ still shows very diffuse streaks associated to the athermal $\omega$ phase, while Ti-(15-17) $\mathrm{Mn}_{\text {MIM }}$ don't show spots or streaks. This is likely caused by the 
$\mathrm{Ti}$

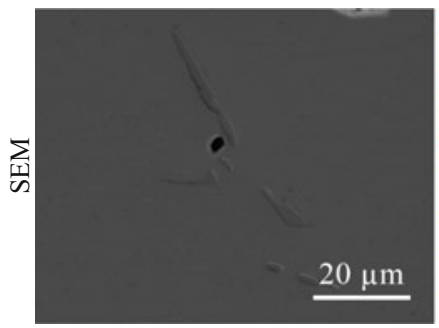

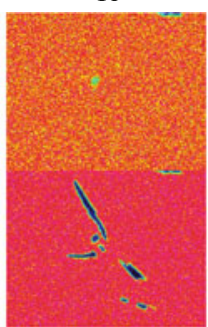

$\mathrm{Mn}$

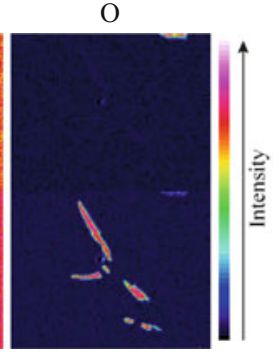

$\mathrm{C}$

Fig. 19.12 SEM image and EPMA elemental mapping images of Ti, Mn, $\mathrm{O}$, and $\mathrm{C}$ in a precipitate in a $\mathrm{Ti}-17 \mathrm{Mn}_{\mathrm{MIM}}$ alloy specimen

higher $\mathrm{O}$ content of the MIM alloys. $\mathrm{O}$ has been reported to inhibit the formation of $\omega$ phase in Ti alloys [24]. Figure 19.12 shows the results of the EPMA analysis of the precipitates. The precipitates are low in $\mathrm{Mn}$ and high in $\mathrm{C}$. The precipitates are thus identified as Ti carbides.

The volume fraction and average diameter of both pores and carbides in the alloys have been estimated from the optical micrographs using an image analysis software [16]. There is no significant variation of either the volume fraction and average diameter of both pores and precipitates among Ti-(8-17) $\mathrm{Mn}_{\mathrm{MIM}}$. However, the shapes of the pores in Ti- $(8-17) \mathrm{Mn}_{\mathrm{MIM}}$ are irregular, although there are no significant differences among the pore morphologies of the alloys. The irregular pore shape is most likely due to the fact that the Mn powder has a more irregular shape compared to the Ti powder [16]. The high $\mathrm{C}$ levels facilitate the formation of carbides. The morphology of the carbides does not particularly vary among Ti-(8-17) $\mathrm{Mn}_{\mathrm{MIM}}$.

Figures 19.13 and 19.14 show the Vickers hardness and Young's modulus of the Ti-(8-17) $\mathrm{Mn}_{\mathrm{MIM}}$ alloys, respectively. The hardness does not significantly vary among the alloys, and they are comparable to that of Ti-64 ELI, indicated by the dashed line in Fig. 19.13 [5]. The Young's moduli of the alloys are all lower than that for annealed Ti-64 ELI, indicated by the dashed line in Fig. 19.14 [5]. Besides the parameters already discussed for the alloys fabricated by CCLM, such as the amount of athermal $\omega$ phase and the effects of increasing Mn, which can affect both hardness and Young's modulus measurements, other parameters must be considered for the alloys fabricated by MIM $[15,16]$. The presence of the pores, which cause localized stress concentration, tends to decrease the hardness of the alloys [23, 25]. Conversely, the presence of carbides, which can cause precipitation strengthening, tends to increase the hardness $[23,25]$. However, because there is little variation of the volume fraction and average diameter of both pores and carbides, these parameters do not cause significant variation of the measured hardness and Young's modulus among the alloys. Furthermore, higher $\mathrm{O}$ contents increase the solid solution hardening effect, which in turn increases the hardness [25-27]. These opposing effects balance each other so that there is little hardness variation among the alloys. 
19 Development and Performance of Low-Cost Beta-Type Ti-Based Alloys...

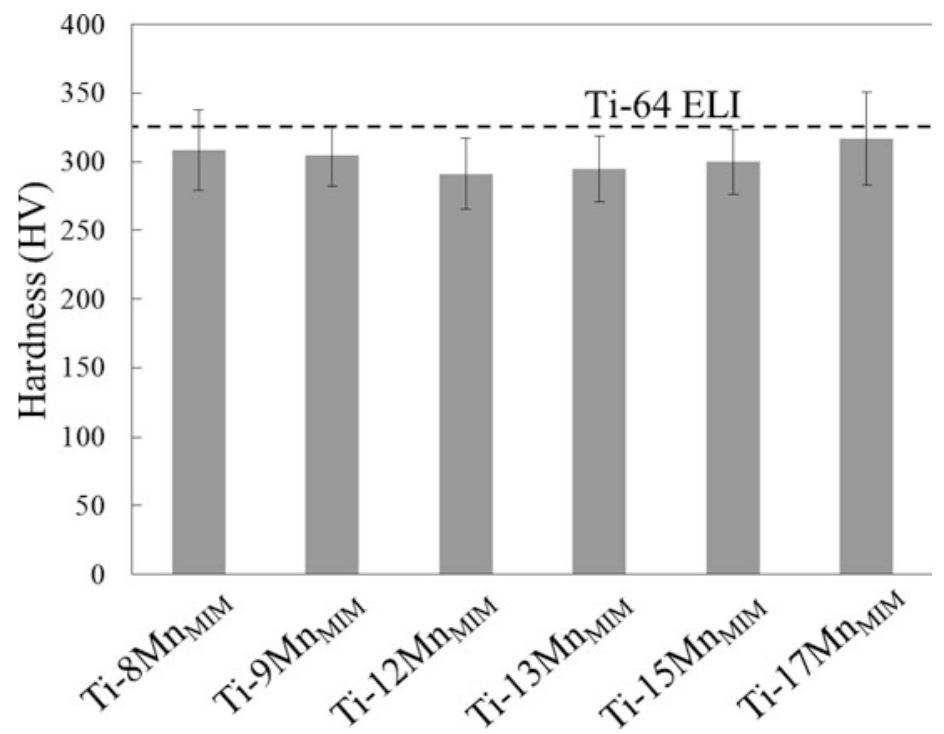

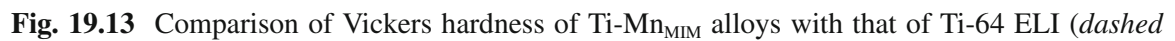
line)

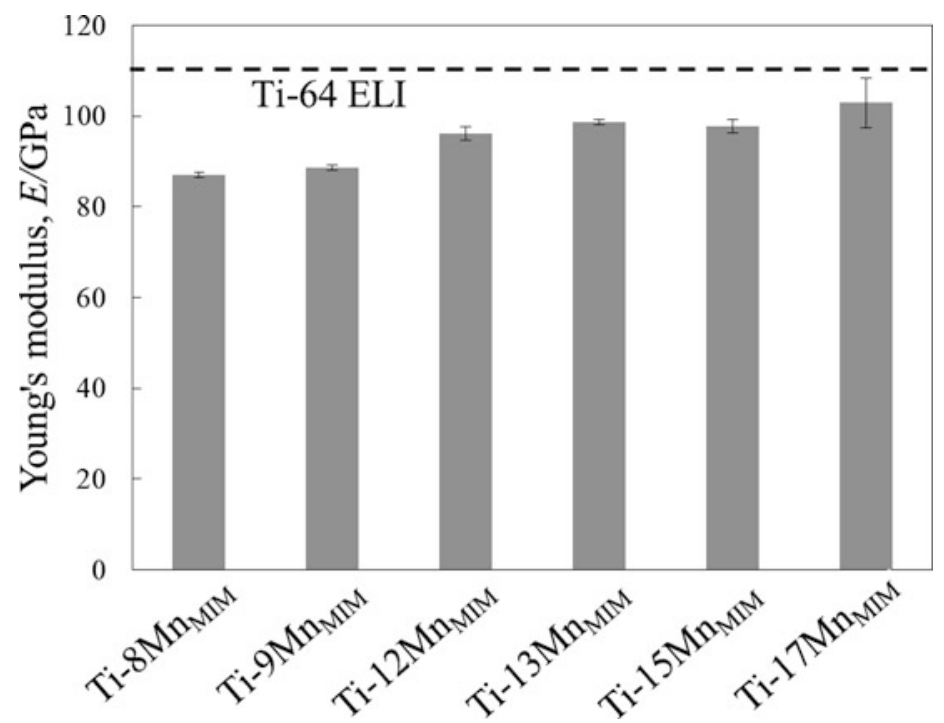

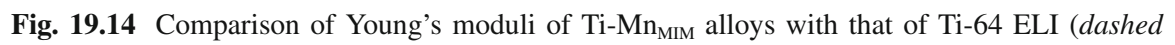
line) 


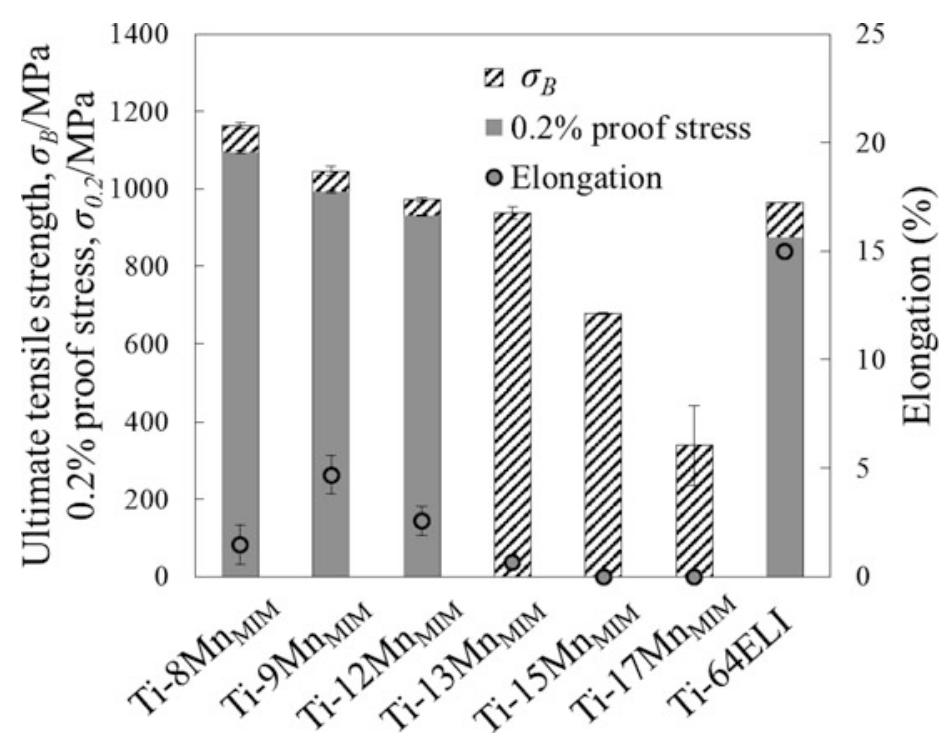

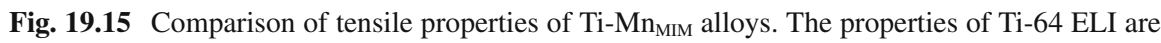
also shown

Figure 19.15 shows the tensile properties of Ti-(8-17) $\mathrm{Mn}_{\text {MIM }}$ along with those of Ti-64 ELI [5]. Both $\sigma_{B}$ and $\sigma_{0.2}$ values for Ti-(8-12) $\mathrm{Mn}_{\text {MIM }}$ are higher than the corresponding values for Ti-64 ELI [5]. However, the elongation of the $\mathrm{Ti}-\mathrm{Mn}_{\mathrm{MIM}}$ alloys is lower than that of annealed Ti-64 ELI. It is noted that the elongation of Ti-Mn ${ }_{\text {MIM }}$, which contains higher $\mathrm{O}$ content, pores, and carbides, is lower than that of $\mathrm{Ti}_{-} \mathrm{Mn}_{\mathrm{LM}}$, which do not contain pores and carbides and have lower $\mathrm{O}$ content. Thus, the lower elongation of Ti- $\mathrm{Mn}_{\text {MIM }}$ can be attributed to the combined effects of a higher $\mathrm{O}$ content primarily, along with the presence of pores and carbides, which are inherent to the MIM process [23, 28, 29].

Figure 19.16 shows the compressive properties of $\mathrm{Ti}-(8-17) \mathrm{Mn}_{\text {MIM. }}$. The compressive $0.2 \%$ proof stress $\left(\sigma_{c 0.2}\right)$ and compressive strain $\left(\varepsilon_{c}\right)$ values for Ti-(8-17) $\mathrm{Mn}_{\text {MIM }}$ are higher than those for Ti-64 [4], also shown in Fig. 19.16. The two main parameters that affect the compressive properties of an alloy are the Mn content (which causes solid solution strengthening) and the amount of the $\omega$ phase (which causes precipitation strengthening). The higher volume fraction of athermal $\omega$ phase in Ti- $8 \mathrm{Mn}_{\text {MIM }}$ and Ti-9Mn $\mathrm{MIM}_{\text {MI }}$ causes their $\sigma_{c 0.2}$ values to be higher than those of $\mathrm{Ti}-(12-17) \mathrm{Mn}_{\text {мIM }}$. As the volume fraction of the athermal $\omega$ phase decreases in $\mathrm{Ti}-(12-15) \mathrm{Mn}_{\text {MIM }}$, the solid solution strengthening effect of the Mn balances the effect of the decreasing $\omega$ phase. The increase in compressive strain with increasing Mn content is also due to the decrease in the volume fraction of the athermal $\omega$ phase with increasing Mn content. 


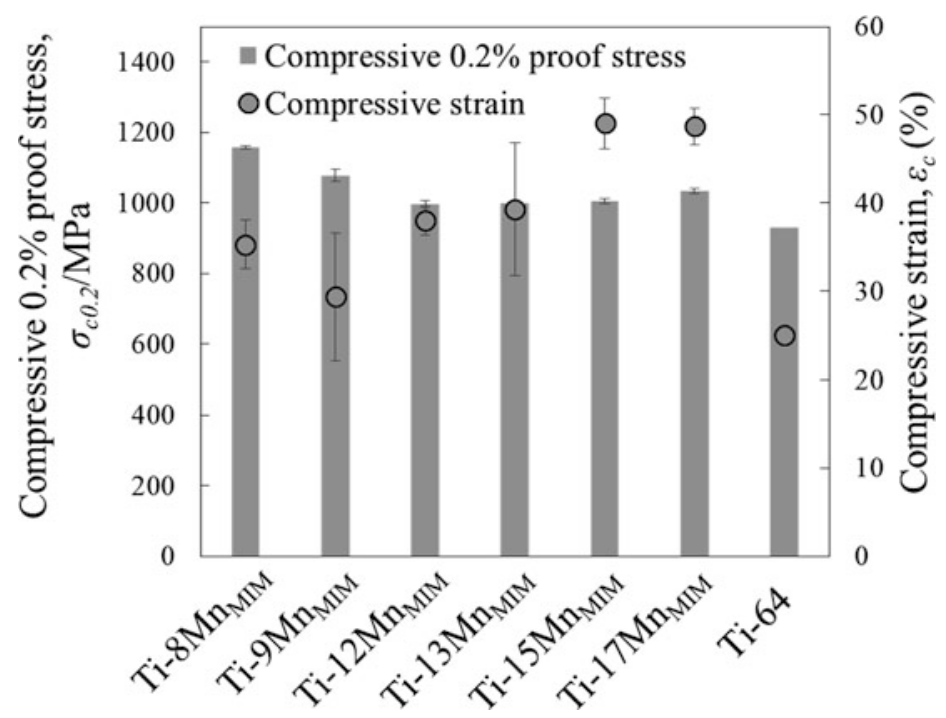

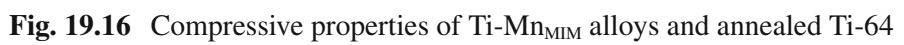

\subsection{Conclusions}

Mn was selected as a low-cost $\beta$-stabilizer alloying element to fabricate Ti alloys of various compositions. The alloys were fabricated by both CCLM and MIM. Microstructural observations, mechanical performance tests, and biocompatibility tests were used to evaluate the mechanical properties and biocompatibility of the fabricated Ti-Mn alloys. Regarding the use of Mn as an alloying element with Ti and the competitive applicability of Ti-Mn alloys, it was possible to conclude that:

1. The alloys are primarily composed of equiaxed $\beta$ grains. Some of the alloys with lower Mn content also contain the athermal $\omega$ phase. The $\beta$ phase stability increases, thus decreasing the volume fraction of the athermal $\omega$ phase, with increasing Mn content. The alloys fabricated by MIM contain high amounts of $\mathrm{O}$ and $\mathrm{C}$, which are due to the powders and organic binder used, respectively. Because of the high $\mathrm{C}$ content, there is the precipitation of $\mathrm{Ti}$ carbide in the alloys fabricated by MIM. Furthermore, the alloys fabricated by MIM also contain pores.

2. The hardness, Young's modulus, and tensile strength of Ti-(9-13) $\mathrm{Mn}_{\mathrm{LM}}$ are comparable or superior to those of Ti-64 ELI. The hardness, Young's modulus, tensile strength, and compressive properties of Ti-(8-13) $\mathrm{Mn}_{\text {MIM }}$ are comparable or superior to those of Ti-64 ELI. However, the ductility of the alloys fabricated by MIM is adversely affected by the high oxygen content and the presence of carbides and pores. 
3. Among both alloys fabricated by CCLM and those fabricated by MIM, Ti-9Mn shows the best balance between tensile strength and ductility. In particular, the Ti-9Mn $\mathrm{MM}_{\mathrm{LM}}$ shows the largest elongation among all the Ti-Mn alloys. Conversely, $\mathrm{Ti}-9 \mathrm{Mn}_{\mathrm{MIM}}$ shows the lowest compressive properties among these alloys.

4. Every Ti-Mn $\mathrm{MM}_{\mathrm{LM}}$ alloy shows ion release rates consistent with their chemical composition when immersed in SBF. Ti-(6-13) $\mathrm{Mn}_{\mathrm{LM}}$ shows good cell viability ratios, which are comparable to those of CP-Ti. However, higher Mn concentrations should be avoided because of risks of Mn intoxication.

Acknowledgments This study was supported in part by a Grant-in-Aid for Scientific Research (A) No. 24246111; a Grant-in-Aid for Young Scientists (B) No. 25820367 from the Japan Society for the Promotion of Science (JSPS); the Inter-University Cooperative Research Program "Innovation Research for Biosis-Abiosis Intelligent Interface" from the Ministry of Education, Culture, Sports, Science and Technology (MEXT), Japan; and the Innovative Structural Materials Association (ISMA), Japan.

\section{References}

1. Geetha M, Singh AK, Asokamani R, Gogia AK. Ti based biomaterials, the ultimate choice for orthopaedic implants - a review. Prog Mater Sci. 2009;54:397-425. doi:10.1016/j. pmatsci.2008.06.004.

2. Niinomi M. Recent metallic materials for biomedical applications. Metall Mater Trans A. 2002;33:477-86. doi:10.1007/s11661-002-0109-2.

3. Niinomi M. Mechanical biocompatibilities of titanium alloys for biomedical applications. J Mech Behav Biomed Mater. 2008;1:30-42. doi:10.1016/j.jmbbm.2007.07.001.

4. Boyer R, Welsch G, Collings EW. Materials properties handbook: titanium alloys. New York: ASM International; 1993.

5. Niinomi M. Mechanical properties of biomedical titanium alloys. Mater Sci Eng A. 1998;243:231-6. doi:10.1016/S0921-5093(97)00806-X.

6. Perl DP. Relationship of aluminum to Alzheimer's disease. Environ Health Perspect. 1985;63:149-53. doi:10.1289/ehp.8563149.

7. Domingo JL. Vanadium and tungsten derivatives as antidiabetic agents: a review of their toxic effects. Biol Trace Elem Res. 2002;88:97-112. doi:10.1385/BTER:88:2:097.

8. Service PH. Public health statement for aluminum. 2008.

9. Bania PJ. Beta titanium alloys and their role in the titanium industry. JOM. 1994;46:16-9. doi:10.1007/BF03220742.

10. Niinomi M, Hattori T, Morikawa K, Kasuga T, Suzuki A, Fukui H, et al. Development of low rigidity $\beta$-type titanium alloy for biomedical applications. Mater Trans. 2002;43:2970-7.

11. Froes FH, Bomberger HB. The beta titanium alloys. JOM. 1985;37:28-37. doi:10.1007/ BF03259693.

12. Pilliar RM, Cameron HU, Binnington AG, Szivek J, Macnab I. Bone ingrowth and stress shielding with a porous surface coated fracture fixation plate. J Biomed Mater Res. 1979;13:799-810. doi:10.1002/jbm.820130510.

13. Erdmann L, Graedel TE. Criticality of non-fuel minerals: a review of major approaches and analyses. Environ Sci Technol. 2011;45:7620-30. doi:10.1021/es200563g.

14. U.S. Department of Energy. Critical materials strategy. 2011.

15. Santos PF, Niinomi M, Cho K, Nakai M, Liu H, Ohtsu N, et al. Microstructures, mechanical properties and cytotoxicity of low cost beta Ti-Mn alloys for biomedical applications. Acta Biomater. 2015. doi:10.1016/j.actbio.2015.08.015. 
16. Santos PF, Niinomi M, Liu H, Cho K, Nakai M, Itoh Y, et al. Fabrication of low-cost beta-type Ti-Mn alloys for biomedical applications by metal injection molding process and their mechanical properties. J Mech Behav Biomed Mater. 2016;59:497-507. doi:10.1016/j. jmbbm.2016.02.035.

17. You B-D, Lee B-W, Pak J-J. Manganese loss during the oxygen refining of high-carbon ferromanganese melts. Met Mater. 1999;5:497-502. doi:10.1007/BF03026165.

18. Ho WF. Effect of omega phase on mechanical properties of Ti-Mo alloys for biomedical applications. J Med Biol Eng. 2008;28:47-51.

19. Williams JC, Hickman BS, Marcus HL. The effect of omega phase on the mechanical properties of titanium alloys. Metall Trans. 1971;2:1913-19. doi:10.1007/BF02913423.

20. Reynolds N, Blumsohn A, Baxter JP, Houston G, Pennington CR. Manganese requirement and toxicity in patients on home parenteral nutrition. Clin Nutr. 1998;17:227-30.

21. Dickerson RN. Manganese intoxication and parenteral nutrition. Nutrition. 2001;17:689-93. doi:10.1016/S0899-9007(01)00546-9.

22. Okazaki Y, Gotoh E, Manabe T, Kobayashi K. Comparison of metal concentrations in rat tibia tissues with various metallic implants. Biomaterials. 2004;25:5913-20. doi:10.1016/j. biomaterials.2004.01.064.

23. German R. Progress in titanium metal powder injection molding. Materials (Basel). 2013;6:3641-62. doi:10.3390/ma6083641.

24. Paton NE, Williams JC. The influence of oxygen content on the athermal beta-omega transformation. Scr Metall. 1973;7:647-9.

25. Esteban PG, Bolzoni L, Ruiz-Navas EM, Gordo E. PM processing and characterisation of Ti-7Fe low cost titanium alloys. Powder Metall. 2011;54:242-52. doi:10.1179/1743290 09X457063.

26. Hammond C, Nutting J. The physical metallurgy of superalloys and titanium alloys. Prog Met Phys. 1977;7:65-163. doi:10.1016/0502-8205(58)90004-2.

27. Ogden HR, Jaffee RI. The effects of carbon, oxygen, and nitrogen on the mechanical properties of titanium and titanium alloys. 1955.

28. Liu H, Niinomi M, Nakai M, Cho K, Narita K, Şen M, et al. Mechanical properties and cytocompatibility of oxygen-modified $\beta$-type $\mathrm{Ti}-\mathrm{Cr}$ alloys for spinal fixation devices. Acta Biomater. 2015;12:352-61. doi:10.1016/j.actbio.2014.10.014.

29. Zhao D, Chang K, Ebel T, Qian M, Willumeit R, Yan M, et al. Microstructure and mechanical behavior of metal injection molded Ti-Nb binary alloys as biomedical material. J Mech Behav Biomed Mater. 2013;28:171-82. doi:10.1016/j.jmbbm.2013.08.013.

Open Access This chapter is distributed under the terms of the Creative Commons Attribution 4.0 International License (http://creativecommons.org/licenses/by/4.0/), which permits use, duplication, adaptation, distribution and reproduction in any medium or format, as long as you give appropriate credit to the original author(s) and the source, provide a link to the Creative Commons license and indicate if changes were made.

The images or other third party material in this chapter are included in the work's Creative Commons license, unless indicated otherwise in the credit line; if such material is not included in the work's Creative Commons license and the respective action is not permitted by statutory regulation, users will need to obtain permission from the license holder to duplicate, adapt or reproduce the material. 